\title{
Editorial
}

\section{Thank you authors and reviewers}

First and foremost I express heartfelt appreciation to all authors and reviewers of the first year of International Journal of Pharmaceutical Investigation (IJPI) on behalf of the entire editorial board and the publisher. It was with the mere cooperation, enthusiasm, and spirit of the authors and reviewers we could make IJPI a grand success.

Authors have been a real motivation and key in establishing IJPI as one of the best journals for publication in the subject of Pharmaceutics. I thank them all in considering and trusting IJPI as the platform for publishing their valuable work. I also thank all authors for their kind co-operation extended during the various stages of processing of the manuscript in IJPI.

For the success of any journal, reviewers are an essential part and therefore the reviewers merit sincere appreciation. IJPI relies on the efforts and benevolence of the reviewers on assessing the suitability of a manuscript for publication in IJPI. The inputs of reviewers are frequently used in improving the quality of a submitted manuscript. The reviewing of a manuscript is very essential to assure the quality of the manuscript published in any journal. I thank all reviewers for their excellent contributions during the first year of IJPI.

It would not be appropriate if I fail to mention the tireless efforts of Dr. Mueen Ahmed K.K (InPharm Association) and Medknow Publications for making IJPI as one of the best journals in Pharmaceutics within a short time span. We are on our way to index IJPI in PubMed and other important journal indexing and abstracting services. We dream of tremendous citations for articles in IJPI and thus a good impact factor in near future. The success of IJPI has really been a motivation and inspiration for me to continue as the Editor-in-Chief for the second year of IJPI. I hope that the co-operation of authors and reviewers to IJPI will continue in its second year.

\begin{tabular}{|l|l|}
\hline \multicolumn{2}{|c|}{ Access this article online } \\
\hline Quick Response Code: & Website: \\
\hline & www.jpionline.org \\
\cline { 2 - 2 } & DOI: \\
\hline
\end{tabular}

The overwhelming responses from the authors and readers have been a real motivation and support in taking forward IJPI to the second year of its existence. I am much pleased to bring before you the second volume of IJPI. IJPI has been striving to excel in publishing quality manuscripts in the field of Pharmaceutics. IJPI has achieved, up to much extent, its mission to be a platform for the rapid dissemination of highquality publications in the entire arena of pharmaceutics. ${ }^{[1]}$

A large number of queries are being received by the authors regarding the suitability of publication of their manuscript, publication charges, manuscript processing time, etc. At this stage, I would once again thrust on these details. IJPI publishes manuscripts coming under entire scope of Pharmaceutics. There are no submission/processing/publication charges from authors for the manuscripts submitted to IJPI. On an average, a time period of 3 weeks is taken for a final decision on a manuscript submitted to IJPI. The authors are requested to comply with the instructions to authors (http://www.jpionline.org/contributors. asp) so that the submitted manuscripts can be processed at the earliest.

I would like to mention it again - Thank you authors and reviewers.

Javed Ali

Editor-in-Chief, International Journal of Pharmaceutical Investigation

Address for correspondence: Dr. Javed Ali, International Journal of Pharmaceutical Investigation, Department of Pharmaceutics, Jamia Hamdard, New Delhi-110 062, India

E-mail: javedaali@yahoo.com

\section{REFERENCE}

1. Ali J, Mueen Ahmed KK. The launch of International Journal of Pharmaceutical Investigation. Int J Pharm Invest 2011;1:1.

How to cite this article: Ali J. Thank you authors and reviewers. Int $\mathrm{J}$ Pharma Investig 2012;2:1 